\title{
Field Case 2 Saudi Arabia: The 300 ft Tar Mat Challenge
}

Stig Lyngra, Saudi Aramco

This presentation reviews the development history and heavy oil characterization of a heavy oil accumulation associated with one of the super-giant Saudi Arabian onshore carbonate fields. This heavy oil accumulation was discovered in 1941 as one of first discoveries on the Arabian Peninsula. The heavy oil has been on continuous production since 1947 as feedstock for a road oil (asphalt) plant, but the total recovery over the last 67 years is less than $2 \%$ of oil-in-place. A pilot production scheme from two horizontal producers was started in 2007, but has been hampered with technical difficulties related to artificial lift.

An extensive data acquisition program to further characterize the reservoir with focus on spatial understanding of the oil properties has been taking place over the past few years. During this evaluation, it has become clear that the mobile heavy oil is underlain by $300 \mathrm{ft}$ of tar that totally separates the oil column from the aquifer. The first pilot injector placed on top of this tar mat was drilled in 2010.

The historical aspects of the development are reviewed, including the spatial oil characterization results and pertinent details related to the pilot producers and injector. The workshop participants will then be prompted to participate in a discussion on what is required for a full development of this heavy oil accumulation. This will also include identifying critical uncertainties that are yet to be assessed and potential for including the $300 \mathrm{ft}$ tar mat as part of the hydrocarbon development resource. 